\title{
Evaluations of Immersion Teaching Strategies in TEFL
}

\author{
Wang Zheng \\ Xiamen University Tan Kah Kee College
}

Keywords: immersion; teaching; language;

\begin{abstract}
Immersion teaching strategies has gained increasing popularity in foreign language education in China. There is evidence that teachers and students find that immersion teaching strategies provides opportunities for comprehensible output and integrated language teaching. This article discusses the implementation of immersion teaching methodology in teaching English as a foreign language (TEFL) and suggests that a preliminary development of immersion environment is necessary. Such an immersion program aims to provide a strong foundation for oral language fluency and proficiency later. Recommendations for research and pedagogy are proposed. For example, it is suggested that a framework be developed to aids teachers in assisting their students to reap the benefits of immersion teaching instructions in English teaching.
\end{abstract}

\section{Historic Background of Immersion Program}

Definition. Language immersion, or simply immersion, is a technique used in bilingual language education in which two languages are used for instruction in a variety of topics, including math, science, or social studies. [1] The languages used for instruction are referred to as the L1 and the L2 for each student. In China, L1 usually refers to official language-mandarin, and L2 refers to English. English teaching program in China has taken on a variety of different approaches outside of the traditional model.

The Origin of Immersion Teaching Program. Although programs differ by country and context, most language immersion programs have the overall goal of promoting bilingualism between the two different sets of language speakers. Research has shown that these forms of bilingual education provide students with overall greater language comprehension and production of the L2 in a native-like manner.

The first language immersion program in which target language was taught as an instructional language started in Quebec, Canada, in 1965.[2] Since the majority language in Quebec is French, English speaking parents wanted to ensure that their children could achieve a high level of French as well as English in Quebec. Since then, French immersion has spread across the country. It led to the situation of French immersion becoming the most common form of language immersion in Canada so far.

The successful case of language immersion program in Quebec has facilitated and promoted the development of immersion teaching around the world

\section{Types of immersion program}

Types of language immersion can be characterized by the total time students spend in the program. In TEFL classroom in China, there are generally two types characterized by learning time:

Total immersion: In total immersion classroom, the instructional language only is English, students spent $100 \%$ of the classroom time listening to English instruction. The main problem of this type of language immersion is students feel hard to understand of more complicated content or if only learned by L2.

Partial immersion: In partial immersion programs, the class time is taught by the teachers using L1 and L2, usually half L1 and half L2. This type of language immersion is more acceptable for students. 


\section{Framework of Immersion Teaching Strategies in China TESL Classroom}

Language Setting and Input Control. According to The input hypothesis proposed by Krashen [3], learners progress in their knowledge of the language when they comprehend language input that is slightly more advanced than their current level. Krashen called this level of input " $i+1$ ", where "i" is the learner's inter-language and " $+1 "$ is the next stage of language acquisition. That means the language setting of teaching material should be a little advanced then their current language level, but still comprehensible to a large extent. When enough comprehensible and appropriate input is provided, language models and teachers provide enough comprehensible language input, then the students makes great progress.

The language setting is insufficient for traditional methods of language teaching, Language input is derived mainly from class activities and authentic materials are usually lacking. Therefore, the use of authentic and diversified language input is preferred. This means a true language setting such as real-life conversations, speeches, lectures or TV and radio program, songs, etc. are necessary for immersion teaching in the classroom. The teaching material should also be as interesting and diversified as possible so that students' motivation will be improved.

The Requirement for Teachers. This program requires teachers to have native or close to native language competence and a good knowledge of the culture in English-speaking countries. So English native speakers or teachers with fluent English are vital to the success of immersion teaching. Lack of qualified teachers for immersion teaching makes it difficult for it to be implemented. Teacher training can be a key issue.

The Allocation of Time. The first issue is about the allocation of time given to each language. Educators thought that more exposure to the students' L2 will lead to greater L2 proficiency. [4] However it is hard for a student to learn abstract and complex knowledge only by L2. So in China, most of the cases, the instructional language is English plus Mandarin because partial language immersion is more acceptable for students.

In China TESL classroom, partial immersion teaching is more frequently adopted as most students feel difficult to understand 100\% English instruction. Many TEFL programs in China provide students 4 classes a week of exposure to English, which means the time of exposure to English in class is less than 4 hours a week. The extent of students' English input outside classroom is key to the success of immersion teaching. Students should be encouraged to create an immersion environment after class to increase language skills. Supplementary practice of a task is therefore necessary.

Integrating Immersion Teaching into Curriculum. Teaching activities in and EFL immersion teaching context can be seen as forming an island in the sea of the native language setting. It is suggested the choice of a practical methodology as one that combined immersion approach (insistence on authentic native language input as a medium for learning) and the traditional Chinese teaching methodology (reliance on activities that focus on the form structure of language: text analysis, grammatical explanations, drills, text and words memorization).The author believes immersion teaching methodology and the Chinese traditional methodology can be complementary to each other. Therefore, it is best that different methodologies be employed in teaching to address the needs of the students and arouse the interest of the students. There should be no conflict between immersion teaching and traditional teaching.

In addition, it is hard for a student to learn abstract and complex knowledge only by English instruction, traditional teaching can served as a preparatory component, which familiarizes the students with grammar, vocabulary and relevant background knowledge.

\section{Implications and Benefits of Immersion Pedagogy}

Studies have shown that students who study a foreign language in school, especially those who start in elementary school, tend to receive higher standardized test scores than students who have not studied a foreign language in school. Students who study foreign languages also tend to have increased mental capabilities and have advantages in the workplace as employers are increasingly 
seeking workers with knowledge of different languages and cultures.[5] Bilingual immersion programs are intended to foster proficiency or fluency in foreign languages and therefore maximize these benefits. Even cases in which fluency in the desired language is not fully attained, immersion programs provide a strong foundation for fluency later in life and help students gain appreciation of languages and cultures that are not their own.

This article discuss the integration of immersion teaching into the traditional language teaching curriculum and a brief framework is developed to aids teachers in assisting their students to reap the benefits of immersion teaching instructions in English teaching.

Finally, we strongly recommend that educators integrate traditional methodologies with the immersion teaching approach to provide a strong immersion environment to help students master a language.

\section{Referencs}

[1] Nascimento, F. C. (2017). Benefits of Dual Language Immersion on the Academic Achievement of English Language Learners. International Journal of Literacies, 24(1), 1-15.

[2] Zuidema, J. (2011). French-Speaking Protestants in Canada : Historical Essays. Leiden: Brill NV.

[3] Krashen, S. (2003). Explorations in Language Acquisition and Use. Portsmouth: Heinemann.

[4] Antoniou, M., Wong, P. M., \& Suiping, W. (2015). The Effect of Intensified Language Exposure on Accommodating Talker Variability. Journal of Speech, Language \& Hearing Research, 58(3), 722-727. doi:10.1044/2015_JSLHR-S-14-0259

[5] Cummins, J. (2009). Bilingual and Immersion Programs. The Handbook of Language Teaching. Malden, MA: Wiley-Blackwell. 